\title{
Truly Interdisciplinary: The ONU ECCS Senior Design Experience
}

\author{
Juliet K. Hurtig \\ John K. Estell \\ Electrical \& Computer Engineering and Computer Science Department \\ Ohio Northern University
}

\section{Abstract}

All seniors in the College of Engineering at Ohio Northern University are required to complete a capstone project. Following the merger of the former Computer Science and Electrical \& Computer Engineering departments in 2001, the Electrical \& Computer Engineering and Computer Science (ECCS) Department developed a year-long, three course senior design sequence common to all three majors offered: computer engineering, computer science, and electrical engineering. This approach allows ECCS students to work on truly interdisciplinary comprehensive projects, and also allows for participation on interdepartmental teams. The students are presented with a mixture of faculty- and industry-sponsored projects and are assigned to project teams based upon their specified preferences. The course sequence requires the students to research an open-ended problem statement, develop a proposal, design a prototype, validate the design, produce a physical deliverable, and report the results. As part of the experience, students deal with various management issues and technical aspects of design. Both written and oral communication of the proposal and final project results are required, and all aspects of project documentation are available on the team's website. Faculty evaluate projects at the end of each quarter through sets of rubrics; external feedback is obtained through project group interactions with the ECCS industrial advisory board and with the local IEEE branch. Two competitions, for the best poster and oral presentations, are held to provide performance incentives. Applying this methodology has improved the overall quality of the project designs and better prepared our graduates for their industrial careers.

\section{Introduction}

In the "2005-2006 Criteria for Accrediting Engineering Programs" published by ABET, Criterion 3(d) states that students must have "an ability to function on multi-disciplinary teams" while Criterion 4 states that students "must be prepared for engineering practice through the curriculum culminating in a major design experience based on the knowledge and skills acquired in earlier course work and incorporating appropriate engineering standards and multiple realistic constraints." In response to these charges, many institutions have incorporated one or more team-oriented senior design courses into their engineering curricula; Ohio Northern University is no exception. In the former Electrical and Computer Engineering (ECE) Department, senior design consisted of a year-long, three quarter sequence of courses. The first course focused on the characteristics of engineering design projects and the development of a project proposal, the second course focused on a comprehensive project, and the third course focused on the 
presentation of technical information from the project. Each senior design team was assigned to its own dedicated project laboratory of approximately 100 square feet in area. Test equipment required for the project could either be used in the instructional laboratories or checked out and housed within the project laboratory. The purchasing of parts and equipment for student projects is subsidized through the Archer Fund, established in the memory of Larry Archer, who was Dean of the ONU College of Engineering for over 30 years. The interest from the endowment is split between the Dean's Office and the departments within the College; the amount available to ECE was in the range of $\$ 4,000-\$ 8,000$ per year, dependent upon investment performance. In order to obtain resources from this fund, students are required to properly fill out and submit a purchase requisition order, thereby providing some real-world paperwork experience in the process. In comparison, the former Computer Science (CS) Department had a two quarter sequence for the senior project, where the first course examined the software life cycle as a vehicle for the production of a problem definition, which was then design and implemented during the second course. All CS project teams were housed within a single room approximately 650 square feet in area dedicated to the senior design experience; each student was furnished with an individual carrel containing a computer. No funds other than general department funds were available for any required purchases.

In 2001, ECE and CS merged to form the Electrical \& Computer Engineering and Computer Science (ECCS) Department, thereby creating a single department with two senior design sequences for three degree programs. This posed a serious problem in and of itself, as having two unequal paths for the fulfillment of the senior design process could harm the esprit de corps of the ECCS student body and potentially affect the relationships between the ECE and CS faculty. Additionally, the computer engineering and electrical engineering programs were preparing for an accreditation visit in fall 2002; the self-study process provided additional motivation to examine the effectiveness of the respective senior design experiences during the 2001-02 academic year as per ABET guidelines. Among the shortcomings observed were the following:

- The CS students demonstrated a clear deficiency in their design ability.

- The ECE students, while demonstrating better aptitude at design than their CS counterparts, also demonstrated shortcomings, particularly in their understanding of standards and constraint analysis.

- Students were evaluated using a ranked scale (excellent, very good, etc.) without any definition as to what these rankings constituted, resulting in grading inconsistencies.

- The CS senior design sequence did not incorporate any technical communication components.

- Projects were selected by the faculty and then presented to the students during the first quarter of the sequence. Design teams requiring specialized equipment or parts for their project had to then quickly place orders and hope for timely arrival in order to complete their project, which unfortunately did not always occur.

- The second course in the ECE sequence did not have any deliverables; as a consequence, student grades were assigned on a purely subjective basis.

To address these shortcomings, several changes were effected in the senior design sequence for all three programs. The most notable changes occurred with computer science. The CS Senior 
Design Laboratory was reorganized by disposing of the individual carrels and replacing them with team-oriented cubicles. Additionally, a shared common area was created to provide access to a whiteboard, a computer with a video projection system, and a meeting table that can comfortably seat up to seven individuals. As they were now part of the College of Engineering, computer science students were also provided access to the Archer Fund for their projects. While software-oriented projects are less likely to require additional resources, it does occur from time to time, plus it is important for student morale within the department that all students are allowed the same opportunities for resources, regardless of discipline. Finally, the computer science curriculum was changed so that, starting in fall quarter 2002, CS students would take the same three course senior design sequence with the ECE students. The ECE senior design sequence to be taken by students from all three degree programs was significantly modified such that projects and teams are selected prior to the senior year, design concepts and team management skills are emphasized, and rigorous methods are employed to evaluate performance. The following four sections examine the changes implemented and discuss the pedagogy employed within each one of the courses that composes the ECCS senior design sequence, as well as the preparations performed prior to starting the sequence.

\section{Preparations}

A successful senior design project requires planning, not only on the part of the students, but also on the part of the instructor supervising the project. Asking a faculty member or an industry contact for a project at the last minute often results in items being overlooked, usually to the detriment of the implementation of the project. Accordingly, project proposals are solicited from the faculty during the spring quarter of the students' junior year, and are made available to the students approximately two weeks prior to advanced registration for fall quarter of the senior year. Proposals are presented in the form of a project statement consisting of one or two paragraphs that provides a general overview of the problem and the proposed solution. Students are asked to indicate their first, second, and third project preferences and submit this information to the department office. The coordinator of the senior design sequence, in consultation with the faculty, assigns students to teams based upon the stated preferences. Students are informed of the results just prior to advanced registration, and are told which section of the first course in the sequence they are to sign up for. This corrected another shortcoming of the previous process employed in the former ECE Department, where students would randomly sign up for sections, then had to be administratively reassigned to the correct section once the design teams were selected around the third week of the quarter, which required a large number of forms to be processed by both the department secretary and the department chair. There are additional benefits to the early team and project selection process. If it is recognized that specialized equipment or parts are required, they can be ordered with a sufficient lead time to ensure arrival by the beginning of the actual work on the project in about six months time; it also allows the department chair the option of ordering at either the end of the current fiscal year or at the beginning of the next fiscal year. Students, having already been formed into teams, can now meet with company representatives to start the process of working on "industry-ready" projects. Finally, as meaningful senior design projects tend to "push the envelope," being cognizant of one's project in the spring allows a student to spend time during the summer to acquire additional knowledge that can be brought to bear upon the design problem. 


\section{Fall Quarter: Senior Design Seminar}

The senior capstone project is not the student's first exposure to formal design work; however, it does challenge students to draw from all of their previous coursework and complete a design that is large enough in scope to require a team effort and a six-month time period. To begin this capstone process, there is a two-credit hour fall quarter course, ECCS 404: Senior Design Seminar, which meets once a week for a 50-minute lecture. The two key course objectives are:

- Participate on a team design project and contribute to the effort by sharing team responsibilities.

- Begin a design process which culminates in the creation of a proposal that incorporates several areas of technical expertise and which requires independent work of group members.

To prepare students for the team project, this course requires students to complete a team charter, which becomes their key team management tool. The bulk of the lectures presented in this course focus on the content of engineering design proposals. The course grade reflects this also, as $50 \%$ of the course grade depends on the team's written proposal and oral presentation made at the end of the quarter. The remaining $50 \%$ is based on the individual student's performance with regards to homework assignments and team responsibilities.

\section{A. Team Management Tools}

The capstone process begins in the fall quarter with each group defining their team charter. The charter functions as a tool to generate and to check shared understandings. Initial charter discussions establish effective team processes and facilitate movement through the stages of group development. ONU's chapter of Tau Beta Pi annually hosts an Engineering Futures ${ }^{2}$ seminar on the roles of teams and team charters, and all senior design groups are strongly urged to participate.

The charter is composed of five parts, and is relatively simple to complete. There is a section for students to identify their strengths, constraints, and goals; their potential roles on the team; the peer-peer evaluation metrics; the evaluation process itself; and methods for constructive feedback and criticism. As the senior capstone timeline advances, and as conflicts occur and the team matures, the charter will need to reflect the group's changing dynamics. Thus, it is imperative that in order to be a useful document, the charter must be updated periodically by all team members.

The peer-peer evaluation is run mid-quarter as a means of practice and to provide students feedback with regards to their performance. At the end of the quarter, an individual's peer-peer evaluation scores will determine $20 \%$ of the course grade. All students are rated on the major proposal activities, five contribution criteria as set by each team, and their overall contribution to the proposal.

Additional tools that improve team efficiency are the usage of log books and team meeting minutes. All students are required to document their time and activity in a log book that is presented to the advisor periodically for review. The log book information is typically compiled into a weekly status report and submitted to their faculty advisor. All teams meet weekly with 
their advisor and minutes must be taken and approved by the team. In 2004-05, two capstone teams are exploring the usage of a WIKI website instead of the traditional paper log book. Electronic files are also conveniently shared and stored on the WIKI site for all team member usage.

\section{B. Engineering Design Proposal}

The capstone proposal begins with a problem identification statement that specifically addresses the history of the problem, the project goals and deliverables, and answers the basic "What?" question. Students are then tasked to complete further research and information gathering, which will support the definition of the project. This typically contains an operational block diagram and any applicable software flow diagrams. The question of "How?" has not been addressed at this point, but is addressed in the next section, which is the development of the plan. Here, various design solutions are proposed and evaluated via decision matrices. The consideration factors that support Criterion 4 are also explicitly addressed. The proposal then presents the best solution for the stated problem and a detailed system block diagram with team member responsibilities assigned to each block. The proposal concludes with an economic budget presentation and the project scheduling and Gantt chart. Weekly lectures and assignments assist students in completing the proposal, and students are encouraged to refer to design (Salt's and Rothery's ${ }^{3}$ ) and technical writing (Alley's ${ }^{4}$ ) textbooks for further assistance.

Criterion 4 states that students must participate in a culminating design experience that incorporates "appropriate engineering standards and multiple realistic constraints." To expose students to engineering standards, all capstone participants must successfully complete ANSI's introductory online course on standards entitled "Why Standards Matter." The course is free, and requires students to complete and pass several online quizzes in order to earn the certificate of completion. The realistic constraints listed in Criterion 3(c) include: economic, environmental, sustainability, manufacturability, ethical, health and safety, social, and political factors. Each student must individually assess their project based on these factors, and then the team as a whole formulates a position on each constraint as presented in their proposal. In 200405 , three-fourths of the seniors were enrolled in a systems engineering course, which covered and addressed most of these factors. (This course utilized Blanchard's and Fabrycky's book. ${ }^{6}$ ) In addition, the Engineering Handbook ${ }^{7}$ produced by the School of Engineering at Santa Clara was utilized as a reference and case study for these eight constraints.

\section{Evaluation of Deliverables}

The course culminates with both the submission of the written project proposal and an oral presentation based upon the proposal. The written proposal is due first, at the end of the ninth week of the quarter, so as to provide sufficient time for faculty review. The oral presentation is then given during the tenth week. All faculty members in the department participate in the review process; however, due to the number of both design teams and faculty members, each written proposal and oral presentation is reviewed by a three to five member committee of the faculty, which allows for both fewer reports to review and the setting up of parallel tracks to speed up the oral presentation process. Each committee is composed of representatives from all three degree programs, thereby providing a broad experience base that can be collectively 
brought to bear upon each proposal and presentation. However, because of the difference in viewpoints amongst this diverse group of faculty, sets of rubrics are employed for the purpose of evaluation. The written proposal employs three separate rubrics: one for the evaluation of the technical writing aspects of the report, one for the evaluation of the technical design aspects of the project, and one specifically for the evaluation of the realistic constraints inherent to the project. The oral presentation employs one rubric that covers elements of oral technical communication skills as applied to the project. Each rubric category is evaluated on a zero to four point scale, where definitions are provided for scores of zero, two, and four; scores of one and three are used when an evaluation falls in between two of the provided definitions. The rubric point system is structured such that a score of two is considered as satisfactory compliance for a given category. Figure 1 provides examples of criteria from the rubric used to evaluate the technical writing aspects of the proposal.

\begin{tabular}{|c|c|c|c|}
\hline $\begin{array}{c}\text { Writing } \\
\text { Mechanics } \\
\text { Criteria }\end{array}$ & $\begin{array}{c}4 \\
\text { Exemplary }\end{array}$ & $\begin{array}{c}2 \\
\text { Satisfactory }\end{array}$ & $\begin{array}{c}0 \\
\text { Unacceptable }\end{array}$ \\
\hline $\begin{array}{l}\text { Visual } \\
\text { Format }\end{array}$ & $\begin{array}{l}\text { The document is visually } \\
\text { appealing. White space and } \\
\text { color are used appropriately } \\
\text { to separate blocks of text and } \\
\text { add emphasis. The reader } \\
\text { can easily navigate the } \\
\text { document. }\end{array}$ & $\begin{array}{l}\text { Use of white space and color } \\
\text { help the reader navigate the } \\
\text { document, although the } \\
\text { layout could be more } \\
\text { effective and appealing. }\end{array}$ & $\begin{array}{l}\text { The document is not visually } \\
\text { appealing and there are few } \\
\text { "cues" to help the reader } \\
\text { navigate the document. }\end{array}$ \\
\hline Grammar & $\begin{array}{l}\text { Sentences are complete and } \\
\text { grammatical. They flow } \\
\text { together easily. }\end{array}$ & $\begin{array}{l}\text { For the most part, sentences } \\
\text { are complete and } \\
\text { grammatical, and they flow } \\
\text { together easily. Any errors } \\
\text { are minor and do not distract } \\
\text { the reader. }\end{array}$ & $\begin{array}{l}\text { Errors in sentence structure } \\
\text { and grammar are frequent } \\
\text { enough that they distract the } \\
\text { reader and interfere with } \\
\text { meaning. }\end{array}$ \\
\hline $\begin{array}{l}\text { Use of } \\
\text { language and } \\
\text { word choice }\end{array}$ & $\begin{array}{l}\text { Words are chosen for their } \\
\text { precise meaning. } \\
\text { Engineering terms and jargon } \\
\text { are used correctly. They are } \\
\text { defined the first time they are } \\
\text { used in the report. }\end{array}$ & $\begin{array}{l}\text { Repetition of the same words } \\
\text { and phrases is avoided. For } \\
\text { the most part, terms and } \\
\text { jargon are used correctly } \\
\text { with some attempt to define } \\
\text { them. }\end{array}$ & $\begin{array}{l}\text { There is unnecessary } \\
\text { repetition of the same words } \\
\text { and phrases. There is an } \\
\text { overuse of jargon and } \\
\text { technical terms without } \\
\text { adequate explanation of their } \\
\text { meaning. }\end{array}$ \\
\hline
\end{tabular}

Figure 1. Example criteria from the technical writing rubric.

Following the evaluation of the proposals and presentations, the faculty return their individual rubric score sheets for each team back to the senior design sequence coordinator, who enters the data into a spreadsheet for tabulating the results. The results for each evaluation category are averaged, weighted to form the total score for each team, and are reported to each faculty team supervisor, who then assigns letter grades based in large part upon this information. The oral presentation and technical design content are each worth $30 \%$, while the written report and the constraint considerations are each worth $20 \%$. An example of such a report is presented in Figure 2. 


\begin{tabular}{|c|c|c|c|c|c|}
\hline Design Team \#1 & Prof A & Prof B & Prof $\mathrm{C}$ & Prof D & Average \\
\hline Oral Presentation (32 pts) & 29 & 23 & 20 & 18 & 22.50 \\
\hline Written Report (36 pts) & 30 & 24 & 18 & 20 & 23.00 \\
\hline Technical Design (24 pts) & 23 & 19 & 16 & 14 & 18.00 \\
\hline \multirow[t]{2}{*}{ Constraints (32 pts) } & 28 & 21 & 16 & 16 & 20.25 \\
\hline & & & & Total \% & 69.03 \\
\hline
\end{tabular}

\begin{tabular}{|c|c|c|c|c|c|}
\hline Design Team \#2 & Prof A & Prof B & Prof C & Prof D & Average \\
\hline Oral Presentation (32 pts) & 25 & 21 & 20 & 15 & 20.25 \\
\hline Written Report (36 pts) & 24 & 18 & 18 & 18 & 19.50 \\
\hline Technical Design (24 pts) & 22 & 16 & 12 & 12 & 15.50 \\
\hline \multirow[t]{2}{*}{ Constraints (32 pts) } & 23 & 18 & 16 & 16 & 18.25 \\
\hline & & & & Total $\%$ & 60.60 \\
\hline
\end{tabular}

\begin{tabular}{|c|c|c|c|c|c|}
\hline Design Team \#3 & Prof A & Prof B & Prof C & Prof D & Average \\
\hline Oral Presentation (32 pts) & 25 & 20 & 20 & 17 & 20.50 \\
\hline Written Report (36 pts) & 29 & 23 & 15 & 21 & 22.00 \\
\hline Technical Design (24 pts) & 23 & 17 & 12 & 14 & 16.50 \\
\hline \multirow[t]{2}{*}{ Constraints (32 pts) } & 25 & 22 & 16 & 16 & 19.75 \\
\hline & & & & Total $\%$ & 64.41 \\
\hline
\end{tabular}

Figure 2. Rubric evaluation report.

\section{Winter Quarter: Senior Design}

ONU's ECCS design process follows a seven-step procedure. The proposal incorporates the areas of problem identification, research and information gathering, definition of the project, and the development of the plan. Winter quarter begins with each student team resolving any comments or suggestions regarding their graded and reviewed proposal. The team is then ready to move on to the next steps: execution of the plan and verification of the design.

If students have not already submitted purchase orders for necessary project equipment, they are encouraged to do so as soon as possible. The students complete purchase orders, which then go through the university's administrative structure and are sent out to the company. The average time it takes to complete this process is 1-2 weeks, including the shipping time from the company. While the department could allow students to make purchases on their own and reimburse them, the purchase order process gives students a good appreciation for the corporate environment of purchasing.

The winter quarter course, ECCS 405: Senior Design, is a three-credit hour course which does not meet for lecture. Instead, each student is expected to log a minimum of nine hours per week working on their project. The students track their hours in a lab book which includes the student's name, the amount of time spent and a brief description of the task addressed. The log 
book is stored in their project lab where it can be accessed by all team members and the faculty advisor. (Note that currently some teams are currently exploring a WIKI site instead of the more traditional paper/pen lab book.) Most faculty advisors will meet weekly with the teams to evaluate progress and require team meeting minutes and other progress report memos.

The course grade is again determined using a rubric system. Each rubric category is evaluated on a zero to four point scale, where definitions are provided for each score. The rubric point system is structured such that a score of two is considered as satisfactory compliance for a given category. However, in this quarter, the grade is determined solely by the team's faculty advisor. The weekly status report, team meetings, and lab log books make up $45 \%$ of the course grade. The students utilize a peer-peer evaluation again for $30 \%$ of their course grade, and an end-ofquarter written or oral progress report makes up the remaining $25 \%$. If chosen, the oral progress report is typically made in front of the department's freshman engineering students. This allows students just entering the program to realize the possibilities of projects and the level of presentations required in the engineering profession.

\section{Spring Quarter: Engineering Technical Communication}

ECCS 406: Engineering Technical Communication, is the last course in the senior design sequence, and is worth three credit hours. Ideally, at this point the design implementation is complete and the project verification indicates that all project specifications have been met. Often delays will occur, and if a project finds itself needing two or three more weeks for completion, the students can continue to work on their designs while the course lectures focus on technical communication issues.

This spring quarter course focuses on the last step of the ECCS Department's seven-step design process, namely communicating the design results. By the end of the quarter, students will complete a final written report, an oral presentation, a project website, and enter a poster competition. Obviously these tasks will require teamwork to accomplish within the course time frame. Students meet for lectures three times a week. The lectures summarize what technical communication requires: to inform and/or persuade the audience. Following the text by Alley, the lectures review structure and organization, language (precise, clear, concise), and illustration. Exercises for memos, letters of transmittal, and identifying the purpose and audience for the communication are assigned to give students opportunities to apply these techniques. Sometimes students feel this is trivial information to be studying in their senior year, as they have been writing lab reports and making oral presentations throughout their undergraduate curriculum. However, the course presents the information to students with the idea that they may eventually be managers; managers have to be able to recognize good and bad communication practices and be able to direct their employees to improve it.

The course grade is based mainly on the group projects $(70 \%)$ with the remaining points earned on an individual basis. This $30 \%$ is composed of homework and attendance $(10 \%)$ and the peerpeer evaluation score (20\%). The group projects are evaluated again with the use of rubrics, with the same point scale as the previous ones. The significant difference this quarter comes via the evaluators, as both faculty and external evaluators are utilized. The final written report and team website are graded by a committee of the department's faculty, just as in the fall quarter course. 
The capstone project websites from previous years are available for viewing on the department website. ${ }^{8}$

The external evaluators enter the process in two poster competitions and the oral presentation. The first poster competition is with the Lima, Ohio IEEE section. Members of this section come to campus for a banquet dinner with the seniors and then judge the posters. The department also schedules an afternoon meeting that day with its industrial advisory board, and invites the members to attend the banquet and participate in the judging. The College's advisory board also judges the posters of all capstone projects later in the quarter. For this event, the posters are hung in the hallways of the building to allow all students to view the posters as they walk to class. These external situations provide situations in which the team members have to assess their audience members and style their presentations appropriately.

Besides their course grade, teams are motivated to do the best they can by two possible awards. One is at the department level, and is awarded to the team that produces the best possible scores in all communication examples of the spring quarter. The other award is at the college level. One capstone project from each department is chosen based on their oral presentation to present at the College's advisory board meeting. In both cases, the project chosen receives their names on a plaque located in the public areas of the college building.

\section{Examples of Projects}

While students from all three degree programs participate together in the lecture and presentation components of the senior design sequence, students from different degree programs do not necessarily work together on projects. The definition of what constitutes a multi-disciplinary team, as called for in Criterion 3(d), is that each member of the team brings unique skills to the table needed for the success of the project; this is not to be interpreted as requiring design teams consisting of one electrical engineer, one computer engineer, etc. However, it is beneficial to have in place a system, such as that described here, which is conducive toward forming teams consisting of students from more than one degree program, as it does allow for the establishment of more interesting projects. The number of seniors in each of the three ECCS degree programs since the establishment of the ECCS Department in 2001 is presented in Table 1, along with the number of capstone projects for that year, the number of design groups with mixed majors, and the number of industrial or externally-sponsored projects. An additional column reflects participation on ECCS design teams by students from the Mechanical Engineering Department.

Table 1: Statistical Data of ECCS Capstone Projects and Senior Students

\begin{tabular}{|c|c|c|c|c|c|c|c|}
\hline & $\begin{array}{c}\text { Computer } \\
\text { Science } \\
\text { Seniors }\end{array}$ & $\begin{array}{c}\text { Computer } \\
\text { Engineering } \\
\text { Seniors }\end{array}$ & $\begin{array}{c}\text { Electrical } \\
\text { Engineering } \\
\text { Seniors }\end{array}$ & $\begin{array}{c}\text { Mechanical } \\
\text { Engineering } \\
\text { Seniors }\end{array}$ & $\begin{array}{c}\text { Number of } \\
\text { Capstone } \\
\text { Projects }\end{array}$ & $\begin{array}{c}\text { Groups } \\
\text { with } \\
\text { Mixed } \\
\text { Majors }\end{array}$ & $\begin{array}{c}\text { Number of } \\
\text { Industrial/External } \\
\text { Sponsored } \\
\text { projects }\end{array}$ \\
\hline $2001-02$ & 17 & 18 & 6 & 0 & 10 & $2^{*}$ & 1 \\
\hline $2002-03$ & 9 & 14 & 17 & 0 & 10 & 5 & 3 \\
\hline $2003-04$ & 11 & 17 & 18 & 6 & 13 & $9^{* *}$ & 5 \\
\hline $2004-05$ & 5 & 6 & 12 & 0 & 6 & 5 & 5 \\
\hline
\end{tabular}

* Both mixed groups consisted of three computer engineering students and one electrical engineering student.

** Four of these nine groups had mechanical engineering student members. 
The 2001-02 data reflects the situation immediately following the merger of the computer science program into the College of Engineering, and is included to illustrate the situation prior to the adoption of the interdisciplinary approach beginning in the 2002-03 academic year. A direct result of the merger and unification of the department to one process for the capstone project is the increased number of projects that require mixed majors, as evidenced by the steady increase from $20 \%$ in $2001-02$ to $80 \%$ in $2004-05$. This ability to have interdisciplinary groups (by major and by their expertise on the team) has also allowed the department to solicit and complete more industrial and external sponsored projects. The department currently has $80 \%$ of its students working with clients other than a faculty member, as compared to a third or less in previous years.

The following examples contain summaries of projects conducted under this senior design sequence that could not have been readily attempted under the previous sequence formats; full descriptions of these projects are available at the ECCS Senior Design Projects web site. ${ }^{8}$

\section{A. Skynet}

The Skynet project involved the development of an automated two-dimensional vision-based position control system for an industrial robot to perform autonomous tasks on objects with inconsistent positions within the designated work area. Two students from mechanical engineering, possessing robotic experience, worked with three ECCS students: a computer engineering major, a computer science major, and an electrical engineering major. The system required the use of two imaging cameras, development of image processing algorithms, a robust user interface, and programming a robot controller interface. Accordingly, students from the various programs had specific tasks in terms of programming, algorithmic development, etc., that called upon the knowledge background of that degree program.

\section{B. Vox Perfecta}

The Vox Perfecta project consists of students from both computer science and electrical engineering developing music software for use in vocal training and musical dictation. The voice training program presents the user with real-time feedback during sessions by superimposing the notes sung by the user over the lesson music whereas the musical dictation program transcribes what the user sings into notes of the appropriate pitch and duration. The two groups of students each brought to the project strengths that the members of the other group had little to no exposure to in their curriculum: the electrical engineers had considerable signal processing experience whereas the computer scientists had considerable programming and user interfacing expertise. Together, they were able to collaborate to develop a system serving a particular need that, separately, neither group could have accomplished.

\section{Fire Fighting Robots}

The 2003-2004 senior design sequence had not one but two teams designing autonomous fire fighting robots for the annual Trinity College Fire Fighting Robot Competition. ${ }^{9}$ Robots designed for this competition must navigate a floor plan containing rooms, hallways, and 
doorways to search for and extinguish a randomly placed lit candle within a specified amount of time. The design must adhere to a published set of constraints concerning the size of the robot, how it operates, and the means used for extinguishing the flame. Both teams consisted of three ECCS students and one mechanical engineering student. The mechanical engineers focused on the robot chassis construction for their respective teams while the ECCS students worked on the design of the embedded controller, electrical system, and real-time software applications. Both teams sent a representative to Hartford, Connecticut and competed with their respective robots in the 2004 Trinity College Fire Fighting Robot Competition.

\section{Industrial PC Based Data Acquisition and Processing System}

Six students (three electrical engineers, two computer engineers, and a computer scientist) worked with a multi-national corporation to design a proprietary force monitoring and analytical measuring system which will be used in conjunction with machining and assembly equipment. The final system consisted of an industrial PC with LCD display, data acquisition card, and a custom user interface which allows the user to control the various applications of the system, and ultimately determine the integrity of the parts being tested. This statistical software is not fixed for specific applications, but rather allows for further customization as needed. The prototype is capable of monitoring industrial processes by creating pressure curves and depth measurements via the data obtained from the inputs. All data collected is stored on a self-maintaining archival hard drive. The computer scientist led the efforts of the user interface, the computer engineers worked on the statistical routines and assisted with some hardware issues, and the electrical engineers focused on the hardware (PC, acquisition card, and harddrive) and sensor interfaces.

\section{E. Auto-Tuning PID for a PLC}

A group of four students -- two computer engineering and two electrical engineering majors -developed an auto-tuning PID (Proportional Integral Differential) control algorithm for implementation in a PLC (Programmable Logic Controller) for a local Ohio firm. The team delivered an algorithm, coded in ANSI-compatible $\mathrm{C}$, that implements a normal PID control operation mode as well as a user-initiated auto-tuning process mode that determines proper tuning parameters. Because this project requires both knowledge of programming tasks and knowledge of controls systems theory, it was well-suited to the multi-disciplinary team. The computer engineering students worked primarily on the algorithm's coding and its compatibility with the hardware, to ensure that it will operate on 8-, 16-, and 32-bit PLCs. The electrical engineering students provided the discrete control system theory, validation methods, and MATLAB testing interface.

\section{Results and Conclusion}

The department is currently conducting its third year of its interdisciplinary senior design sequence. The results from the last two years have been favorable in almost all aspects. Student evaluation of the sequence has been very positive, with responses in such categories as opportunity to apply knowledge, use of design methodology, communications skills, emphasis of continuous learning skills, and responsibilities all averaging above 4 on a 5 -point scale, where 5 
indicates strong agreement and 1 indicates strong disagreement. In addition, student comments from all three disciplines were also positive. Many indicated that senior design was their favorite course as it involved a hands-on real world experience where it was fun to work as part of a team that takes a starting idea and, through application of placing their various skills to work, have an actual working product at the end. Faculty course assessment reports also indicate the effectiveness of the approach being used. The data obtained from the rubrics used for various aspects of course outcome evaluation throughout the sequence indicate that all students passing the courses are performing at an effective or higher level of competence.

With respect to the computer science program, it has been observed by the CS faculty that the modifications made to the senior design sequence have resulted in CS-specific projects that are far superior to those conducted under the previous sequence. This improvement is in large part due to the use of a structured framework and exposure to design considerations that are typical of engineering problem solving techniques. There have also been several instances where a CS student has worked as a member of an interdisciplinary team, providing valuable skills not normally found in the typical electrical engineering or computer engineering student. The synergy exhibited by these "discipline-mixed" teams has allowed for the development of projects greater in both scope and complexity than those conducted previously by the former ECE and CS departments.

There are some areas where additional refinement is warranted. The assessment of Criteria 3(c) and 4 is predicated on measuring the success to which design teams deal with realistic constraints; however, some of the definitions of the eight constraints listed in Criterion 3(c) are vaguely defined, if at all, by the engineering profession. The work being conducted at Santa Clara as embodied in their Engineering Handbook is a valued first step in addressing this problem; however, a consensus needs to be reached amongst engineering educators as to what definitions should be employed and what constraints are appropriate to each discipline. This question does have bearing upon the constraint analysis rubric being used in this senior design sequence, as both student teams and faculty evaluators need to use a common set of definitions. Additionally, as each project will involve a different set of design constraints, the scoring of this component of the course needs to accurately reflect how well the team effectively handled those constraints that are pertinent to their design, which is usually a subset of the eight listed in Criterion 3(c). A second area of concern is with regard to written reports. Currently, while students are provided with guidance concerning the content of the reports, there are no guidelines concerning the format of the reports. As a consequence, readers are confronted with a jumbled variety of student-derived formats, some of which work, some of which do not. A better approach, currently under discussion, would be the adoption of an "Author's Guide" similar to that published by ASEE or IEEE where specifications are given as to font type, style, and size, margins, figures, footnotes, and references. Not only would this make life easier for those who have to review the reports, it would provide students with another real-world experience in that many companies do have established formats for written reports that their employees are expected to follow.

The ECCS Department at Ohio Northern University has solved its problems concerning the required culminating major design experience through the implementation of a three course sequence required by all students in their senior year. The common exposure to the design 
process along with the various viewpoints brought forth and shared by the various disciplines has resulted in a better and richer experience for the students. While not perfect, this pedagogical approach to team-oriented senior design has improved the overall quality of the projects and has better prepared students for their industrial careers.

\section{Bibliography}

1. Criteria for Accrediting Engineering Programs (2005-2006 Accreditation Cycle). ABET, Inc. Nov. 1, 2004 [Online]. Available: http://www.abet.org/criteria.html

2. Tau Beta Pi Engineering Futures Program. Tau Beta Pi Association, Inc. 2004 [Online]. Available: http://www.tbp.org/pages/whatwedo/EF.cfm

3. J. E. Salt and R. Rothery, Design for Electrical and Computer Engineers, John Wiley \& Sons, Inc., 2002.

4. M. Alley, The Craft of Scientific Writing, 3rd ed. New York: Springer-Verlag, Inc., 1996.

5. Why Standards Matter. ANSI Education and Training Services. 2002 [Online course]. Available: http://www.standardslearn.org

6. Blanchard and Fabrycky, Systems Engineering and Analysis, 3rd edition, Prentice Hall, 1998.

7. Engineering Handbook: Issues in the Profession of Engineering. School of Engineering, Santa Clara University. T. Healy, Ed., Version 1.1, 2004 [Online]. Available: http://www.scu.edu/engineering/undergraduate/hb.cfm

8. ECCS Senior Design Projects. ECCS Department, Ohio Northern University. 2002 [Online]. Available: $\mathrm{http} / / / w w w . o n u . e d u /$ engineering/eccs/seniordesign/

9. Trinity College Fire Fighting Robot Contest. Trinity College. 2005 [Online]. Available: http://www.trincoll.edu/events/robot/

\section{Biographical Information}

JULIET K. HURTIG is an Associate Professor of Electrical Engineering and Assistant Dean of the T.J. Smull College of Engineering. Her doctorate is from The Ohio State University. Research interests include control systems, nonlinear system identification, and undergraduate pedagogical methods. Dr. Hurtig is a member of IEEE, ASEE, and Tau Beta Pi.

JOHN K. ESTELL became Chair of the Electrical \& Computer Engineering and Computer Science Department at Ohio Northern University in 2001. He received his BS (1984) degree in computer science and engineering from The University of Toledo and received both his MS (1987) and $\mathrm{PhD}$ (1991) degrees in computer science from the University of Illinois at Urbana-Champaign. His areas of interest include simplifying the program outcomes assessment process, interface design and PDA applications. Dr. Estell is a Senior Member of IEEE, and a member of ACM, ASEE, Tau Beta Pi, Eta Kappa Nu, and Upsilon Pi Epsilon. 